\title{
Ammonium nutrition interacts with iron homeostasis in Brachypodium distachyon
}

\author{
Marlon De la Peña ${ }^{1}$, Agustín Javier Marín-Peña ${ }^{1}$, Leyre Urmeneta ${ }^{1}$, Inmaculada Coleto', \\ Jorge Castillo-González², Sebastiaan M. van Liempd ${ }^{3}$, Juan M. Falcón-Pérez ${ }^{3,4,5}$, Ana Álvarez-Fernández², \\ María Begoña González-Moro' and Daniel Marino ${ }^{1,5, *,(\mathbb{D})}$ \\ ${ }^{1}$ Department of Plant Biology and Ecology, University of the Basque Country (UPV/EHU), E-48940, Leioa, Spain \\ 2 Department of Plant Nutrition, Aula Dei Experimental Station, Consejo Superior de Investigaciones Científicas (EEAD-CSIC), E-50059, \\ Zaragoza, Spain \\ ${ }^{3}$ Metabolomics Platform, CIC bioGUNE-BRTA, Derio, Spain \\ ${ }^{4}$ Centro de Investigación Biomédica en Red de enfermedades hepáticas y digestivas (CIBERehd), Madrid, Spain \\ ${ }^{5}$ Ikerbasque, Basque Foundation for Science, E-48011 Bilbao, Spain
}

* Correspondence: daniel.marino@ehu.eus

Received 14 July 2021; Editorial decision 15 September 2021; Accepted 16 September 2021

Editor: Stanislav Kopriva, University of Cologne, Germany

\begin{abstract}
Most plant species develop stress symptoms when exposed to high ammonium $\left(\mathrm{NH}_{4}{ }^{+}\right)$concentrations. The root is the first organ in contact with high $\mathrm{NH}_{4}{ }^{+}$and therefore the first barrier to cope with ammonium stress. In this work, we focused on root adaptation to ammonium nutrition in the model plant Brachypodium distachyon. Proteome analysis revealed changes associated with primary metabolism, cell wall remodelling, and redox homeostasis. In addition, it showed a strong induction of proteins related to methionine (Met) metabolism and phytosiderophore (PS) synthesis in ammonium-fed plants. In agreement with this, we show how ammonium nutrition impacts Met/S-adenosyl-Met and PS metabolic pathways together with increasing root iron content. Nevertheless, ammonium-fed plants displayed higher sensitivity to iron deficiency, suggesting that ammonium nutrition triggers impaired iron utilization and root to shoot transport, which entailed an induction in iron-related responses. Overall, this work demonstrates the importance of iron homeostasis during ammonium nutrition and paves a new way to better understand and improve ammonium use efficiency and tolerance.
\end{abstract}

Keywords: Ammonium, Brachypodium, iron, metabolism, methionine, nitrate, nitrogen, phytosiderophores, root.

\section{Introduction}

Plants take up nitrogen $(\mathrm{N})$ from the soil mostly in the form of nitrate $\left(\mathrm{NO}_{3}{ }^{-}\right)$and ammonium $\left(\mathrm{NH}_{4}^{+}\right)$. Regardless of the $\mathrm{N}$ source, $\mathrm{N}$ assimilation into biomolecules occurs from $\mathrm{NH}_{4}^{+}$ incorporation into carbon $(\mathrm{C})$ skeletons, and thus the direct uptake of $\mathrm{NH}_{4}{ }^{+}$bypasses the energy-consuming $\mathrm{NO}_{3}{ }^{-}$reduction process (Marschner, 2012). Importantly, ammonium-based 
nutrition in combination with nitrification inhibitors has been shown to lower the negative impact $\mathrm{N}$ fertilization has on the environment (Beeckman et al., 2018; Huérfano et al., 2018).

Apart from N, plants need 16 other essential nutrients to complete their life cycle. Genetic, physiological, and biochemical interactions among elements have been reported (Bouain et al., 2019). In particular, the $\mathrm{N}$ source is known to interact with the acquisition and homeostasis of other macro- and micronutrients. For instance, it has been extensively reported that plants grown under $\mathrm{NH}_{4}{ }^{+}$supply display a lower content of cations such as potassium $\left(\mathrm{K}^{+}\right)$, calcium $\left(\mathrm{Ca}^{2+}\right)$, and magnesium $\left(\mathrm{Mg}^{2+}\right)$ with respect to nitrate nutrition because of their direct competition with the uptake of $\mathrm{NH}_{4}^{+}$(Van Beusichem et al., 1988; Roosta and Schjoerring, 2007). In addition, molecular players that connect $\mathrm{NO}_{3}^{-}$signalling to phosphorus (P) deficiency have been identified, such as the $\mathrm{NO}_{3}{ }^{-}$transporter NPF7.3/NRT1.5 (Cui et al., 2019) or the transcription factor HRS1 (hypersensitive to low Pi-elicited primary root shortening) (Medici et al., 2015). $\mathrm{NH}_{4}{ }^{+}$also appears to promote $\mathrm{P}$ remobilization of the cell wall (Zhu et al., 2016). Moreover, the $\mathrm{N}$ source interacts with sulfur (S). For instance, ammonium nutrition enhances sulfate assimilation and uptake (Van Beusichem et al., 1988; Gerendás et al., 1997; Coleto et al., 2017). Although less attention has been paid to the interactions of micronutrients with the $\mathrm{N}$ source, recent works have provided support for the interaction between $\mathrm{NH}_{4}{ }^{+}$and iron $(\mathrm{Fe})$ homeostasis in rice (Zhu et al., 2018) and Arabidopsis (Zhu et al., 2019; Coleto et al., 2021). Among others, $\mathrm{NH}_{4}{ }^{+}$supply was reported to promote Fe release from the cell wall probably through the stimulation of nitric oxide synthesis (Zhu et al., 2018, 2019).

When $\mathrm{NH}_{4}{ }^{+}$is present at high concentrations in the soil, it provokes a marked stress to most plant species, and interactions with other nutrients appear essential for plants to deal with ammonium stress. For instance, the concentration of $\mathrm{K}^{+}$ in the medium has been extensively shown to be associated with ammonium stress symptoms (Balkos et al., 2010; Coskun et al., 2014). In addition, the increase of Fe supply also improved Arabidopsis thaliana growth under ammonium nutrition (Coleto et al., 2021).

$\mathrm{Fe}$ is an important determinant in building prosthetic groups of proteins such as $\mathrm{Fe}-\mathrm{S}$ clusters and haem groups, which means that Fe participates in many essential plant functions (e.g. chlorophyll synthesis and electron transfer between PSI and PSII). Thus, any defect in Fe availability has a great impact on plant growth and quality. $\mathrm{Fe}$ is often present in insoluble complexes with low bioavailability, particularly in calcareous/ alkaline soils (Briat et al., 2015). To face this limitation, plants have developed two strategies to solubilize $\mathrm{Fe}$ in the rhizosphere. Most flowering plants display the so-called strategy I or reduction-based strategy. However, graminaceous species, display strategy II or the chelation-based strategy. Exceptionally, rice has acquired a combined strategy (Ricachenevsky and Sperotto, 2014). Strategy I is a three-step process that starts with proton release from the roots to increase local $\mathrm{Fe}^{3+}$ solubility. Then, $\mathrm{Fe}^{3+}$ is reduced to $\mathrm{Fe}^{2+}$ by a plasma membranebound ferric reductase. Finally, $\mathrm{Fe}^{2+}$ is taken up by the root via IRTs (iron-regulated transporters). In strategy II, graminaceous plants synthesize compounds of the mugineic acid (MA) family called phytosiderophores (PSs) that are released into the rhizosphere via TOM1 (transporter of mugineic acid family phytosiderophores 1). PSs bind $\mathrm{Fe}^{3+}$, forming $\mathrm{Fe}^{3+}-\mathrm{PS}$ complexes that enter into root cells by Yellow Stripe/Yellow Stripe-Like (YS/YSL) transporters (Hindt and Guerinot, 2012; Kobayashi et al., 2019). Since Fe solubility increases with decreasing $\mathrm{pH}$, and $\mathrm{NH}_{4}{ }^{+}$uptake is known to provoke proton release to the apoplast and rhizosphere, ammonium nutrition has been shown to sometimes increase the absorption of nutrients such as $\mathrm{P}, \mathrm{Fe}$, or manganese (Mn) (Thomson et al., 1993).

In the present work, we further studied plant adaptation to ammonium nutrition in Brachypodium distachyon, a widely accepted model for grasses and cereals (Kellogg, 2015). We mostly focused our effort at the root level, since it is the primary site of contact with $\mathrm{NH}_{4}{ }^{+}$and may act as a physiological $\mathrm{NH}_{4}{ }^{+}$ barrier preventing its translocation to aerial parts (GonzálezMoro et al., 2021). To tackle this objective, we performed a proteomic analysis that, among others, revealed alterations of methionine (Met) metabolism and Fe homeostasis under ammonium nutrition. In general, we provide clear evidence of the close interaction between ammonium stress and Fe homeostasis in B. distachyon.

\section{Materials and methods}

\section{Plant growth and experimental design}

Brachypodium distachyon $\mathrm{Bd} 21$ plants were grown in hydroponic conditions as described by De la Peña et al. (2019). Briefly, 11-day-old seedlings were transferred to aerated hydroponic conditions and grown for $19 \mathrm{~d}$ with $1.25 \mathrm{mM}\left(\mathrm{NH}_{4}\right)_{2} \mathrm{SO}_{4}$ or $1.25 \mathrm{mM} \mathrm{Ca}\left(\mathrm{NO}_{3}\right)_{2}$ as $\mathrm{N}$ source. Nitrate-fed plants were supplemented with $1.25 \mathrm{mM} \mathrm{CaSO}_{4}$ to balance the $\mathrm{SO}_{4}{ }^{2-}$ supplied with the $\mathrm{NH}_{4}{ }^{+}$. For Fe deficiency treatment, plants were grown in hydroponic conditions for $7 \mathrm{~d}$ with optimal Fe supply [100 $\mu \mathrm{M} \mathrm{NaFe(III)-EDTA]} \mathrm{and} \mathrm{then} \mathrm{subjected} \mathrm{to} \mathrm{Fe} \mathrm{deprivation} \mathrm{(-Fe)}$ for $12 \mathrm{~d}$. To maintain the $\mathrm{pH}$ stability and the concentration of mineral elements of the hydroponic medium, the nutrient solution was renewed on days 7,11, 14, and 17. Plants were harvested between $10.00 \mathrm{~h}$ and $12.00 \mathrm{~h}(2 \mathrm{~h}$ after the onset of the photoperiod). Shoots and roots were separated and individually weighed. Plants grown in the same tank were pooled, immediately frozen in liquid nitrogen, homogenized in a Tissue Lyser (Retsch MM 400), and stored at $-80^{\circ} \mathrm{C}$ until use.

\section{Proteomic analysis}

A $10 \mathrm{mg}$ aliquot of freeze-dried root powder was resuspended in $0.4 \mathrm{ml}$ of $8 \mathrm{M}$ urea, homogenized using a vortexer, and disrupted by sonication. After centrifugation at $13000 \mathrm{~g}$, the supernatant was collected. Protein integrity was checked by SDS precipitation with 2D CleanUp (GE Healthcare) according to the manufacturer's instructions, re-suspended in RapiGest $0.2 \%$ (Waters), and the protein concentration was determined (BCA assay; Thermo Fisher Scientific). A $75 \mu \mathrm{g}$ aliquot of protein was heated $\left(85^{\circ} \mathrm{C}, 15 \mathrm{~min}\right)$, reduced with DTT $(5 \mathrm{mM})$, alkylated with iodoacetamide $(15 \mathrm{mM})$, and digested with trypsin $(1.5 \mathrm{mg})$ overnight at 
$37^{\circ} \mathrm{C}$ (Roche Diagnostics). RapiGest was inactivated twice by the addition of $\mathrm{HCl}$ at a final concentration of $0.5 \%$ and incubation at $37{ }^{\circ} \mathrm{C}$ for $40 \mathrm{~min}$. Samples were centrifuged at $16000 \mathrm{~g}$ for $10 \mathrm{~min}$, the supernatant was collected, and $25 \mu \mathrm{g}$ of protein was desalted using C-18 Micro SpinColums (Harvard Apparatus). Finally, samples were dried down in a SpeedVac centrifuge (ThermoFisher Scientific).

Mass spectrometry (MS) analyses were performed on an EASY-nLC 1200 liquid chromatography (LC) system interfaced with a Q Exactive HF-X mass spectrometer (ThermoFisher Scientific) via a nanospray flex ion source. Dried peptides were dissolved in $0.1 \%$ formic acid and loaded onto an Acclaim PepMap100 pre-column $(75 \mu \mathrm{m} \times 2 \mathrm{~cm}$, ThermoFisher Scientific) connected to an Acclaim PepMap RSLC C18 $(75 \mu \mathrm{m} \times 25 \mathrm{~cm}$, ThermoFisher Scientific) analytical column. Peptides were eluted in a linear gradient from $2 \%$ to $30 \%$ acetonitrile in $0.1 \%$ formic acid at a flow rate of $300 \mathrm{nl} \mathrm{min}{ }^{-1}$ during $150 \mathrm{~min}$. The mass spectrometer was operated in positive ion mode. Full MS scans were acquired from $\mathrm{m} / \mathrm{z}$ 375 to 1800 with a resolution of 60000 at $\mathrm{m} / z 200$. The 15 most intense ions were fragmented by higher energy C-trap dissociation with a normalized collision energy of 28 , and MS/MS spectra were recorded with a resolution of 15000 at $\mathrm{m} / z 200$. The maximum ion injection time was $60 \mathrm{~ms}$ for survey and MS/MS, whereas automatic gain control (AGC) target values were $3 \times 106$ and $5 \times 105$, respectively. In order to avoid repeat sequencing of peptides, dynamic exclusion was applied for 20 s. Singly charged ions or ions with an unassigned charge state were also excluded from MS/MS. Data were acquired using Xcalibur software (ThermoFisher Scientific).

Acquired raw data files were processed with the MaxQuant (Cox and Mann, 2008) software (version 1.6.0.16) using the internal search engine Andromeda (Cox et al.,2011) and searched against the UniProt database restricted to B. distachyon entries (release 2017_08). Carbamidomethylation was set as a fixed modification, whereas Met oxidation and protein $\mathrm{N}$-terminal acetylation were defined as variable modifications. Mass tolerance was set to $8 \mathrm{ppm}$ and $20 \mathrm{ppm}$ at the MS and MS/MS level, respectively. Enzyme specificity was set to trypsin, allowing for a maximum of three missed cleavages. Match between runs option was enabled with a 1.5 min match time window and a 20 min alignment window to match identification across samples. The false discovery rate (FDR) for peptides and proteins was set to $1 \%$. Normalized spectral protein label-free quantification (LFQ) intensities were calculated using the MaxLFQ algorithm. MaxQuant output data were filtered with the Perseus module (version 1.6.0.7) (Tyanova et al., 2016). Proteins identified by site (identification based only on a modified peptide), reserve proteins (identified by a decoy database), and potential contaminants were filtered out. Proteins with three LFQ values in at least one group were used for quantification, and missing LFQ intensity values were replaced with values from a normal distribution (width 0.3 and down shift 1.8), meant to simulate expression below the detection limit (Tyanova et al., 2016).

\section{Determination of metabolites}

To quantify Met, S-methylmethionine (SMM), S-adenosylmethionine (SAM), S-adenosylhomocysteine (SAH), decarboxylated SAM (dc-SAM), and methylthioadenosine (MTA), $10 \mathrm{mg}$ of tissue powder was homogenized in $500 \mu \mathrm{l}$ of methanol:10 $\mathrm{mM}$ acetic acid $(50: 50, \mathrm{v} / \mathrm{v})$ in a tissue homogenizer (FastPrep). Then $400 \mu \mathrm{l}$ of the homogenate were mixed with $400 \mu \mathrm{l}$ of chloroform and shaken for $60 \mathrm{~min}$ at $1400 \mathrm{rpm}$ at $40^{\circ} \mathrm{C}$. Mixtures were then centrifuged for $30 \mathrm{~min}$ at $13000 \mathrm{rpm}$ and supernatants were evaporated in a SpeedVac. Pellets were resuspended in $150 \mu \mathrm{l}$ of water:acetonitrile $(40: 60, \mathrm{v} / \mathrm{v})$. Metabolites were quantified by LC:MS using a UPLC system (Acquity, Waters) coupled to time-of-flight (ToF) MS (SYNAPT G2 HDMS, Waters) in positive electrospray ionization (ESI) in full scan mode.

Nicotianamine (NA) and PSs [MA and analogous chelators: 2'-deoxymugineic acid (DMA), deoxydistichonic acid A (DDA), distichonic acid A (DA), avenic acid (AA), and 3-hydroxymugineic acid (HMA)] were quantified as described in Díaz-Benito et al. (2018). Briefly, $100 \mathrm{mg}$ of tissue powder was extracted with $200 \mu \mathrm{l}$ of ultrapure water containing nicotyl-lysine as internal standard. The homogenate was vortexed for $30 \mathrm{~s}$, sonicated for $5 \mathrm{~min}$, and centrifuged at $15000 \mathrm{~g}$ for $10 \mathrm{~min}$ at $4{ }^{\circ} \mathrm{C}$. The supernatant was recovered, filtered $(3 \mathrm{kDa}$ cellulose Amicon_Ultra filter units, Merck KGaA), vacuum-dried, and the dry residues dissolved in $20 \mu \mathrm{l}$ of ultrapure water. Aliquots of $5 \mu \mathrm{l}$ of extracts were mixed with $25 \mu \mathrm{l}$ of $20 \mathrm{mM}$ EDTA and $30 \mu \mathrm{l}$ of $10 \mathrm{mM}$ ammonium acetate:acetonitrile (1:9, $\mathrm{pH} 7.3)$, and the mixture was filtered through a $0.45 \mu \mathrm{m}$ polyvinylidene fluoride (PVDF) filter. Quantification was performed by LC:MS using an Alliance 2795 HPLC system (Waters) coupled to a ToF mass spectrometer (MicrOTOF, Bruker Daltonics) equipped with an ESI source. Pure NA and DMA were used as standards.

$\mathrm{NH}_{4}{ }^{+}$was extracted from $20 \mathrm{mg}$ of frozen shoot and root powder in $650 \mu \mathrm{l}$ of ultrapure water, homogenized at $27 \mathrm{~Hz}$ for $1 \mathrm{~min}$, heated at $80{ }^{\circ} \mathrm{C}$ for $5 \mathrm{~min}$, centrifuged at $4000 \mathrm{~g}$ for $20 \mathrm{~min}$, and the supernatant recovered.The quantification was performed following the phenol hypochlorite method in a 96-well microplate reader (Sarasketa et al., 2016).

Chlorophyll was quantified spectrophotometrically from shoot tissue extracted in $80 \%$ aqueous acetone as described in De la Peña et al. (2019).

$\mathrm{Fe}$ and zinc $(\mathrm{Zn})$ were extracted from $10 \mathrm{mg}$ of freeze-dried shoot and root with $\mathrm{HNO}_{3}$ by microwave-assisted digestion (Mars6, Vertex) and quantified by inductively connected plasma MS (ICP-MS; Thermo Fisher Scientific).

\section{Gene expression analysis}

RNA extraction was carried out from $25 \mathrm{mg}$ of frozen shoot or root powder with the Nucleospin RNA plant kit (Macherey-Nagel) that includes DNase treatment. A $1 \mu \mathrm{g}$ aliquot of RNA was retrotranscribed into cDNA (PrimeScript ${ }^{\mathrm{TM}} \mathrm{RT}$; Takara Bio) and gene expression was determined from $2 \mu \mathrm{l}$ of cDNA diluted 1:10 in a $15 \mu \mathrm{l}$ reaction volume using SYBR Premix ExTaq ${ }^{\text {TM }}$ (Takara Bio) in a Step One Plus Real Time PCR System (Applied Biosystems). ACT3 and UBC18 were used as housekeeping genes to normalize gene expression. Absence of genomic DNA contamination was checked in all RNA samples. Primers used are described in Supplementary Table S1.

\section{Statistical analysis}

Data were analysed with SPSS 17.0 (Chicago, IL, USA) or R software v. 3.4.4. Normality and homogeneity of variance were analysed by Kolmogorov-Smirnov and Levene's tests. Student's $t$-tests or one-way ANOVA followed by a Duncan post-hoc test were used to compare sample groups. Non-normally distributed data were analysed with the Mann-Whitney U-test for non-parametric data.

\section{Results}

Ammonium nutrition impacts root primary metabolism, redox balance, and cell wall biogenesis

Ammonium nutrition often reduces plant growth, and that is also the case for B. distachyon (Supplementary Table S2; De La Peña et al., 2019; Glazowska et al., 2019). To further understand root adaptation to ammonium nutrition, we carried out a label-free quantitative proteomic study and analysed the relative abundance of proteins in $B$. distachyon roots grown under ammonium or nitrate nutrition. A total of 4506 distinct proteins were identified with an FDR $<1 \%$ (Supplementary 
Table S3), and 4109 were quantified. Of these, 475 showed differential abundance, with a significant level of $P<0.05$ and 1.5-fold change (FC) cut-off, where 243 proteins presented higher abundance in roots of ammonium-grown plants and 232 higher abundance in roots of nitrate-grown plants (Supplementary Table S3; Supplementary Fig. S1). Biological process Gene Ontology enrichment analysis (PANTHER 14.1; www.pantherdb.org) revealed 139 significantly enriched functional classes (Fisher's exact test $P \leq 0.0$; Benjamini-Hochberg FDR $\leq 0.05), 68$ with up- and 71 with down-regulated proteins (Supplementary Table S4).

In Fig. 1A, B, the most specific over-represented functional classes are shown. As reported in many species including B. distachyon (De la Peña et al., 2019; González-Moro et al., 2021), the N source had a great impact on root primary metabolism. In agreement with this, enriched classes were related to $\mathrm{C}$ and $\mathrm{N}$ metabolism (e.g. glycolytic process, carbohydrate metabolic process, or carboxylic acid catabolic process). Among others, proteome data corroborated the down-regulation of GS2 ('glutamine synthetase chloroplastic' I1J2T4) already observed in ammonium-fed $B$. distachyon at the gene expression level (De la Peña et al., 2019) and in other species, such as Arabidopsis (Sarasketa et al., 2016). The up-regulation of asparagine synthetase (I1IV86) is also in agreement with the huge root Asn accumulation reported in De la Peña et al. (2019). Moreover, GDH2 (I1J084), a classical marker of plant response to ammonium nutrition (Loulakakis and RoubelakisAngelakis, 1991; González-Moro et al., 2021), was up-regulated in roots of ammonium-fed B. distachyon plants (Supplementary Table S3). Regarding C metabolism enzymes, among others, pyruvate kinase (I1HEH4), a cytosolic triose phosphate isomerase (I1HC04), hexokinase (A0A0Q3IMN1), and citrate synthase (I1HYA2) were up-regulated under ammonium nutrition (Supplementary Table S3).

Besides $\mathrm{C}$ and $\mathrm{N}$ metabolism, enriched categories highlighted cell redox balance (e.g. 'response to oxidative stress', 'cellular oxidant detoxification') and cell wall biogenesis and metabolism ('cinnamic acid biosynthetic process', 'L-Phe catabolic process'). Cell wall remodelling is key for cell expansion; loosening of the wall allows the cell to expand, whereas cross-linking between their polymers inhibits cell expansion. Several reports have shown a relationship between ammonium nutrition and cell wall biogenesis and organization (Podgórska et al., 2017; Glazowska et al., 2019; Royo et al., 2019). In our work, we found decreased abundance of three xyloglucan endotransglucosylase/hydrolases (XTHs) in ammonium-fed roots (I1I257, I1I258, and I1IGTU3) and proteins associated with phenylpropanoid biosynthesis including lignin; among others, three phenylalanine ammonia lyase enzymes, a probable 4-coumarate-CoA ligase 3 (I1IHXV5), and a caffeoylCoA O-methyltransferase 1 (I1H0Q2) (Supplementary Table S2). Indeed, Royo et al. (2019) showed differential abundance of cell wall-associated proteins and higher lignin deposition in Medicago truncatula plants grown in ammonium nutrition.
In addition, Podgórska et al. (2017) reported higher cell wall stiffness under ammonium nutrition, overall suggesting that $\mathrm{NH}_{4}{ }^{+}$-mediated growth inhibition could be related to a more rigid cell wall structure.

\section{Ammonium nutrition enhances the Met cycle and the synthesis of phytosiderophores, leading to $\mathrm{Fe}$ accumulation}

Among the functional classes over-represented when analysing the proteins with higher abundance in ammonium-fed plants, categories related to the Met salvage cycle and NA biosynthesis ('L-methionine salvage from methylthioadenosine', 'S-adenosylmethionine biosynthetic process', 'nicotianamine biosynthetic process') were those with the highest fold enrichment (Fig. 1B; Supplementary Table S4). Indeed, enzymes of almost every step of the Met salvage cycle were up-regulated with ammonium nutrition (Figs 1C, 2).

The Met salvage cycle and NA biosynthesis are related to the synthesis of PSs, and thus to the uptake of metals, notably $\mathrm{Fe}$ and $\mathrm{Zn}$ (Kobayashi et al., 2005). In agreement with this, 20 proteins related to $\mathrm{Fe}$ homeostasis were found to be regulated by the $\mathrm{N}$ source (Fig. 1C). We confirmed this result by analysing the expression of nine protein-encoding genes (Supplementary Fig. S2), selected among the 20 Fe-related proteins (Fig. 1C). Thus, we focused on better understanding the impact of ammonium nutrition on Met-associated pathways and complemented the proteome data with an in-depth quantification of Met/SAM derivatives, NA, and PSs by LC:MS.

In agreement with the proteome profile, striking differences were found in the content of most metabolites analysed as a function of the $\mathrm{N}$ source provided. Ammonium nutrition provoked a decrease in root Met content and in the SAM derivatives SAH, dcSAM, and MTA, while SAM content did not vary. In contrast, SMM content increased in ammonium-fed roots (Fig. 2). The effect of the nutrition type on these compounds in shoots was similar to that in roots (Supplementary Fig. S3). Regarding PS content, five out six of the MAs were higher in ammonium nutrition (Fig. 2). Among them, the content of MA, which represented $\sim 90 \%$ of the total content of MAs, was 7.6-fold higher under ammonium nutrition. Moreover, the accumulation of NA was 13.5-fold higher under ammonium with respect to nitrate nutrition. Both proteome data and PS analysis clearly suggested a potential increase of Fe uptake in ammonium-fed plants. Accordingly, the content of Fe was higher in the root of plants grown with $\mathrm{NH}_{4}{ }^{+}$with respect to those grown with $\mathrm{NO}_{3}{ }^{-}$supply (Fig. 3).

\section{The nitrogen source influences B. distachyon response to Fe deficiency}

Due to the finding of the higher root PS and Fe content under ammonium nutrition, we hypothesized that $B$. distachyon response to Fe deficiency could be altered as a function of the 
A

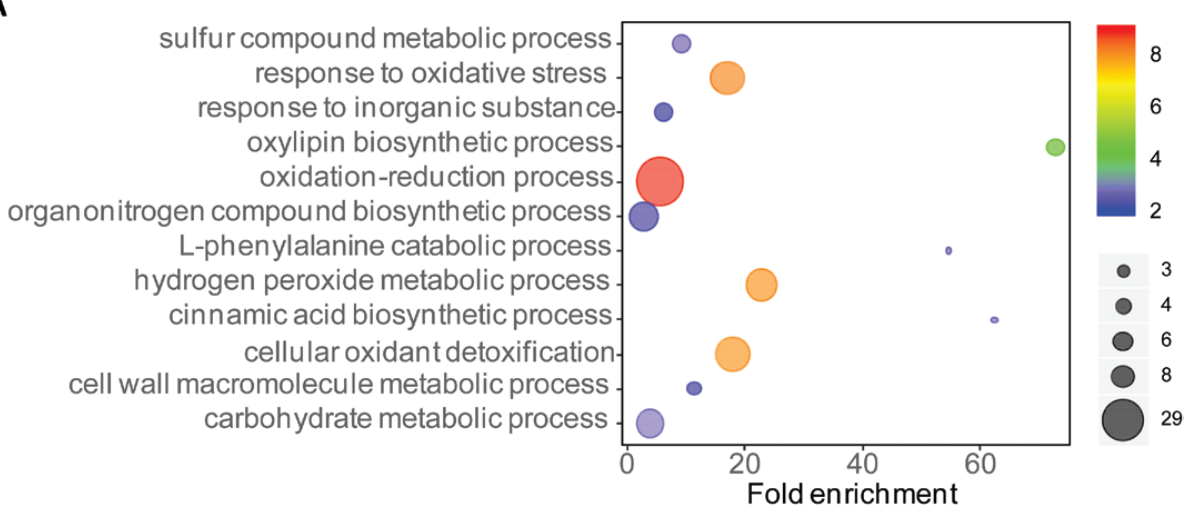

B

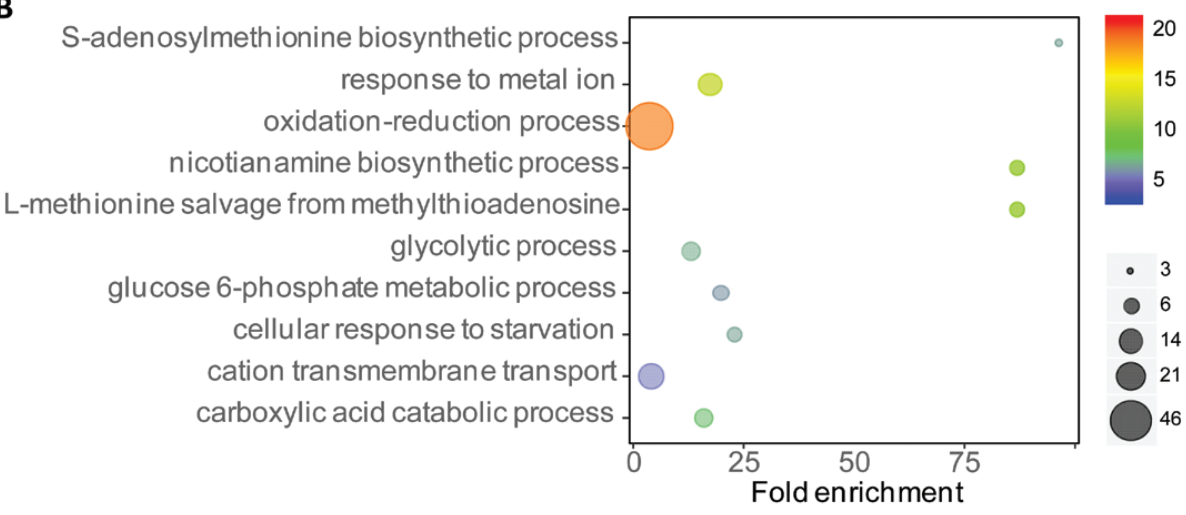

C

\begin{tabular}{|c|c|c|c|}
\hline Uniprot code & Gene ID & Protein description & $\begin{array}{l}\log _{2} \mathrm{FC} \\
\begin{array}{lll}7 & 0 \quad 3 .\end{array}\end{array}$ \\
\hline I1HF18 & LOC100843457 & S-Adenosylmethionine synthase 1 & 1.22 \\
\hline I1HF17 & LOC100844978 & S-Adenosylmethionine synthase 3 -like & 0.99 \\
\hline I1H1W0 & LOC100839737 & 5'-Methylthioadenosine/S-adenosylhomocysteine nucleosidase 2-like & 1.00 \\
\hline I1IMJ 2 & LOC100834960 & Methylthioribose-1-phosphate isomerase & 1.60 \\
\hline I1IES2 & LOC100828599 & Probable bifunctional methylthioribulose-1-phosphate dehydratase & 1.87 \\
\hline $11 / 366$ & LOC100837535 & Methylthioribose kinase 2 & 1.93 \\
\hline I1GTE3 & LOC100837759 & 1,2-dihydroxy-3-keto-5-methylthiopentene dioxygenase 2 & 2.15 \\
\hline IIIAD2 & LOC100829217 & Nicotianamine synthase-like 5 protein & 2.50 \\
\hline I1HZL5 & LOC100822873 & Nicotianamine synthase 2-like & 2.52 \\
\hline $11 \mathrm{H} 680$ & LOC100832895 & Probable nicotianamine synthase 2 & 1.18 \\
\hline I1HZX5 & LOC100831451 & Nicotianamine aminotransferase A-like & 3.60 \\
\hline I1GYH1 & LOC100822209 & Nicotianamine aminotransferase A-like & 0.74 \\
\hline I1|L44 & LOC100841166 & Nicotianamine aminotransferase A-like & 0.68 \\
\hline I1IUR4 & LOC100823408 & 2'-Deoxymugineic-acid 2'-dioxygenase-like & 2.67 \\
\hline I1J071 & LOC100826305 & Probable metal-nicotianamine transporter YSL9-like & 3.52 \\
\hline I1IP67 & LOC100837011 & Ferrochelatase-2, chloroplastic & 0.95 \\
\hline $\mathrm{I} 1 \mathrm{H} 8 \mathrm{CO}$ & LOC100845842 & Metal transporter Nramp2 & 1.40 \\
\hline I1IV67 & LOC100837024 & Ferritin-1, chloroplastic & -4.67 \\
\hline I1GUN7 & LOC100837457 & CDGSH iron-sulfur domain-containing protein NEET & -2.41 \\
\hline I1HBL2 & LOC100825497 & Uncharacterized protein (SUF_FeS_clus_asmbl_SufBD) & -1.07 \\
\hline
\end{tabular}

Fig. 1. Gene Ontology enrichment analysis of proteins with lower $(A)$ and higher abundance $(B)$ in ammonium-fed with respect to nitrate-fed $B$. distachyon plants. Only the most specific significant categories are represented. The colour scale represents the - $\log _{10}(P$-value), and dot size indicates the number of proteins. (C) Proteins related to iron homeostasis displaying differential abundance as a function of the $\mathrm{N}$ source provided.

$\mathrm{N}$ source provided. To test this hypothesis, we subjected plants adapted to ammonium or nitrate nutrition to Fe deficiency $(-\mathrm{Fe})$. As expected, we found that $-\mathrm{Fe}$ condition provoked a substantial decrease in plant growth and chlorophyll content independently of the $\mathrm{N}$ source provided (Fig. 4). However, root growth inhibition provoked by ammonium nutrition was more evident in $\mathrm{Fe}$ deficiency, with root biomass being reduced by $26 \%$ in control conditions and by $40 \%$ under $\mathrm{Fe}$ 


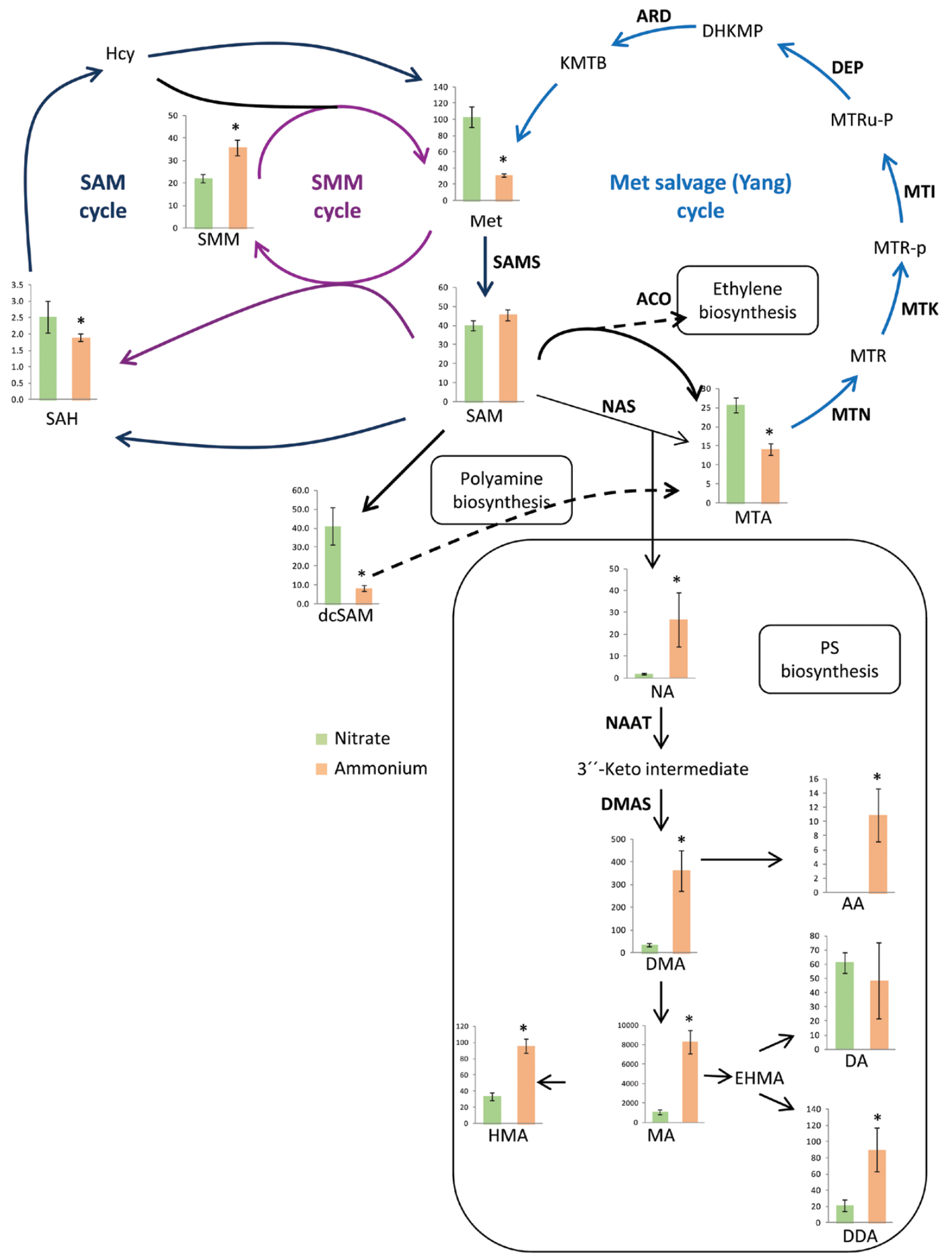

Fig. 2. Content of Met/SAM derivatives, NA, and PSs in roots of $B$. distachyon grown under ammonium or nitrate nutrition. Columns represent the mean values \pm SE $(n=4)$ expressed in nmol $\mathrm{g} \mathrm{FW}^{-1}$, except for dcSAM which is given in relative units. An asterisk indicates significance differences between the $\mathrm{N}$ source analysed $(P<0.05)$. Enzymes shown in the diagram are those that displayed significantly higher abundance under ammonium nutrition in the proteomic analysis. AA, avenic acid; ACO, 1-aminocyclopropane-1-carboxylate oxidase; ARD, acireductone dioxygenase or 2-keto-methylthiobutyric acid-forming enzyme; DA, distichonic acid A; dcSAM, decarboxylated SAM; DDA, deoxydistichonic acid A; DEP, methylthioribulose-1-phosphate dehydratase-enolase-phosphatase; DHKMP, 1,2-dihydro-3-keto-5- methylthiopentene; DMA, 2'-deoxymugineic acid; EHMA, 3-epi-hydroxymugineic acid; Hcy, homocysteine; HMA, 3-hydroxymugineic acid; KMTB, 2-oxo-4-methylthiobutyrate; MA, mugineic acid; Met, methionine; 


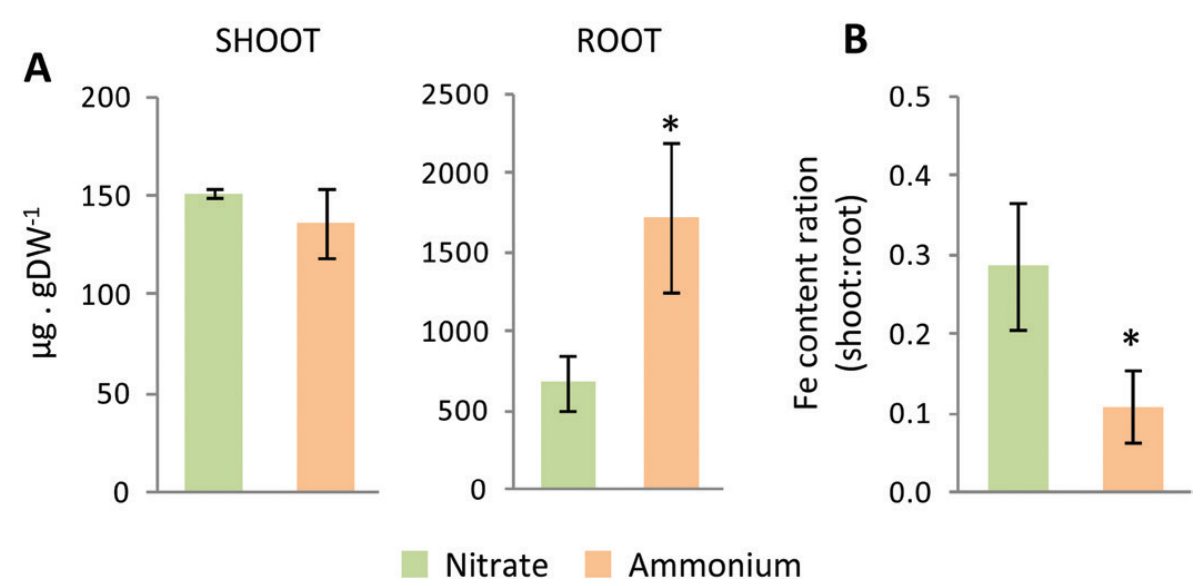

Fig. 3. Fe content in shoots and roots (A) and Fe content ratio (B) of $B$. distachyon grown under ammonium or nitrate nutrition. Columns represent the mean values $\pm \operatorname{SE}(n=4)$. An asterisk indicates a significance difference between the $N$ source analysed $(P<0.05)$.

deficiency in ammonium-fed compared to nitrate-fed plants (Fig. 4). Importantly, this lower growth under Fe deficiency was not due to impaired Fe uptake, since Fe content was higher under ammonium nutrition compared with nitrate nutrition (Fig. 5A). In agreement with PS synthesis induction, Zn content was greatly increased with ammonium nutrition under $\mathrm{Fe}$ deficiency (Fig. 5B). Overall, the results suggest that although Fe uptake is increased in ammonium nutrition, Fe availability is compromised. Indeed, the fact that the content of the cellular Fe storage protein ferritin was $\sim 25$ times lower in roots under ammonium nutrition $\left(\log _{2} \mathrm{FC}-4.67\right)$ supports this hypothesis (Fig. 1C). In addition, the exclusive accumulation of $\mathrm{Fe}$ at the root level (Figs 3-5) suggests that $\mathrm{Fe}$ root to shoot transport may be compromised under ammonium nutrition.

We analysed by quantitative PCR (qPCR) the expression of marker genes associated with Fe deficiency and observed that most genes were already induced in Fe-supplied (control) ammonium-fed plants (Fig. 6; Supplementary Fig. S4). In roots, the higher FRLD1, IDEF2, and YSL2 expression compared with nitrate-fed plants was maintained under Fe deficiency (Fig. 6). Root NAAT and DMAS expression did not respond to $\mathrm{Fe}$ deprivation under ammonium nutrition since their expression was already maximal under control conditions. Also, in agreement with ferritin content (Fig. 1C), FER1 gene expression was lower in ammonium-fed plants in both roots and shoots (Fig. 6; Supplementary Fig. S4).

Finally, we determined $\mathrm{NH}_{4}{ }^{+}$accumulation, a classic marker of ammonium stress. Interestingly, $\mathrm{Fe}$ deficiency greatly enhanced $\mathrm{NH}_{4}{ }^{+}$accumulation, notably at the root level (Fig. 7A), which in turn was correlated with higher amino acid abundance (Fig. 7B). Overall, as suggested by the proteomic study, physiological data and micronutrient analysis confirm the close interaction between Fe homeostasis and ammonium nutrition in B. distachyon.

\section{Discussion}

Ammonium nutrition provoked a clear induction of Fe-deficiency responses in B. distachyon, as evidenced by the stimulation of the Met salvage cycle and PS synthesis (Figs $1,2)$, together with the higher expression of Fe deficiencyresponsive genes (Fig. 6; Supplementary Fig. S4). Graminaceous species take up Fe following a chelation-based strategy (commonly known as Strategy II) and, as a consequence, Fe deficiency stimulates the synthesis of PSs (NA and MAs). NA is synthesized by NA synthase (NAS) from the combination of three units of SAM. In addition, SAM is the precursor of many other biomolecules such as polyamines and ethylene. In these reactions, such as NA synthesis, MTA is released and can be recycled again to Met or SAM thanks to the Met salvage cycle, also known as the Yang cycle (Kobayashi et al., 2005; Sauter et al., 2013). Indeed, the Met salvage cycle is highly active in the root and it is also induced under Fe deficiency to enable this organ to meet the increased demand for SAM required for the synthesis of MAs (Ma et al., 1995; Kobayashi et al., 2005).

To sustain PS synthesis, Strategy II plants need proper SAM availability, which demands sulfate $\left(\mathrm{SO}_{4}{ }^{2-}\right)$ uptake and assimilation. These two processes have been suggested to increase under ammonium nutrition (Van Beusichem et al., 1988; Gerendás et al., 1997; Coleto et al., 2017). Following this same line of evidence, ammonium-fed $B$. distachyon roots displayed higher abundance of ATP sulfurylase 1 (I1GNF6) and other sulfurrelated proteins under ammonium nutrition (Supplementary

MTA, 5-methylthioadenosine; MTI, 5-methylthioribose-1-phosphate isomerase; MTK, 5-methylthioribose kinase; MTN, MTA nucleosidase; MTR, 5-methylthioribose; MTR-P, 5-methylthioribose-1-phosphate; MTRu-P, 5-methylthioribulose-phosphate; NA, nicotianamine; NAAT, NA-aminotransferase; NAS, nicotianamine synthase; PS, phytosiderophore; SAH, S-adenosylhomocysteine; SAM, S-adenosyl-Met; SAMS, S-adenosyl-Met synthetase; SMM, $S$-methylmethionine. 

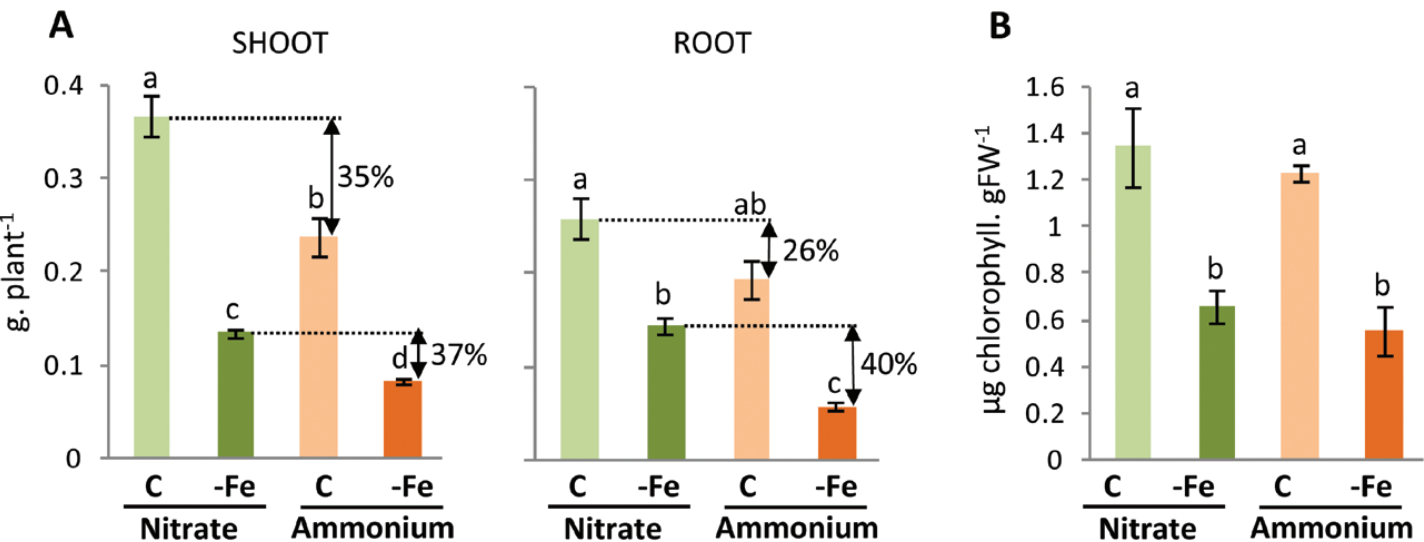

Fig. 4. Biomass and chlorophyll content of $B$. distachyon. Biomass (A) and chlorophyll content (B) of $B$. distachyon grown under ammonium or nitrate nutrition under control $(\mathrm{C})$ or Fe deficiency $(-\mathrm{Fe}$ ) conditions. Columns represent the mean values $\pm \mathrm{SE}$ ( $n=30$ for biomass, $n=6$ for chlorophyll). Different letters indicate significant differences according to one-way ANOVA followed by Duncan's test $(P<0.05)$.
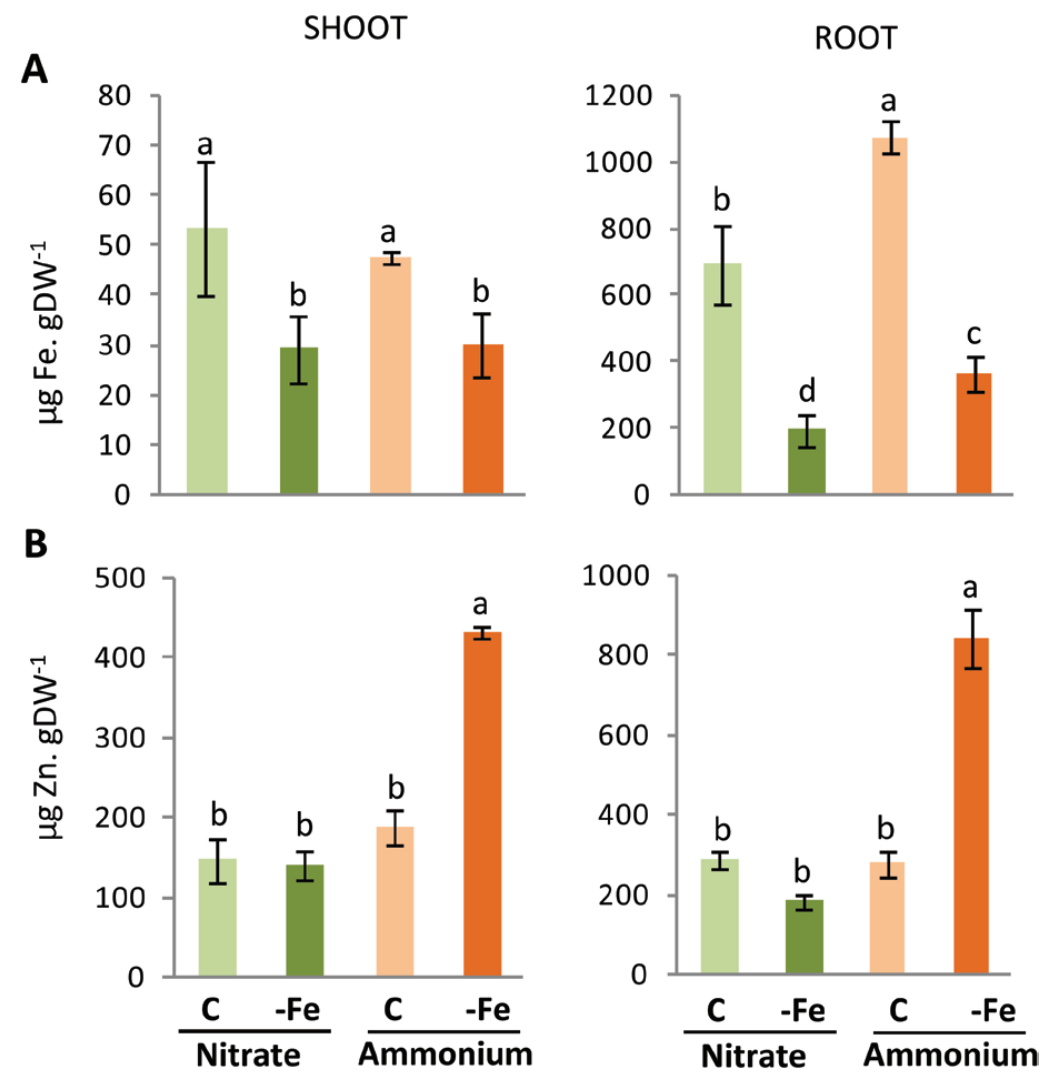

Fig. 5. Iron and zinc content in B. distachyon. Iron (A) and zinc (B) content in B. distachyon grown under ammonium or nitrate nutrition under control (C) or Fe deficiency $(-F e)$ conditions. Columns represent mean values $\pm S E(n=3)$. Different letters indicate significant differences according to one-way ANOVA followed by Duncan's test $(P<0.05)$.

Table S3). Indeed, while most SAM intermediates were reduced in ammonium-fed plants, SAM content remained equal to that of nitrate-fed plants (Fig. 2; Supplementary Fig. S3). Interestingly, despite the Met level being reduced, the SMM content increased under ammonium nutrition (Fig. 2; Supplementary Fig. S3). SMM is considered to be the mobile and storage form of Met and may also be involved in the tolerance of plants to abiotic stresses (Ogawa and Mitsuya, 2012). The reason the SMM level increases while that of other Met/SAM derivatives decreases is unknown and is a question to be tackled in future studies.

As expected in view of the striking enhancement of PS synthesis, root $\mathrm{Fe}$ content increased in the root of ammonium-fed plants (Fig. 3). Stimulation of Fe uptake by $\mathrm{NH}_{4}{ }^{+}$supply has 

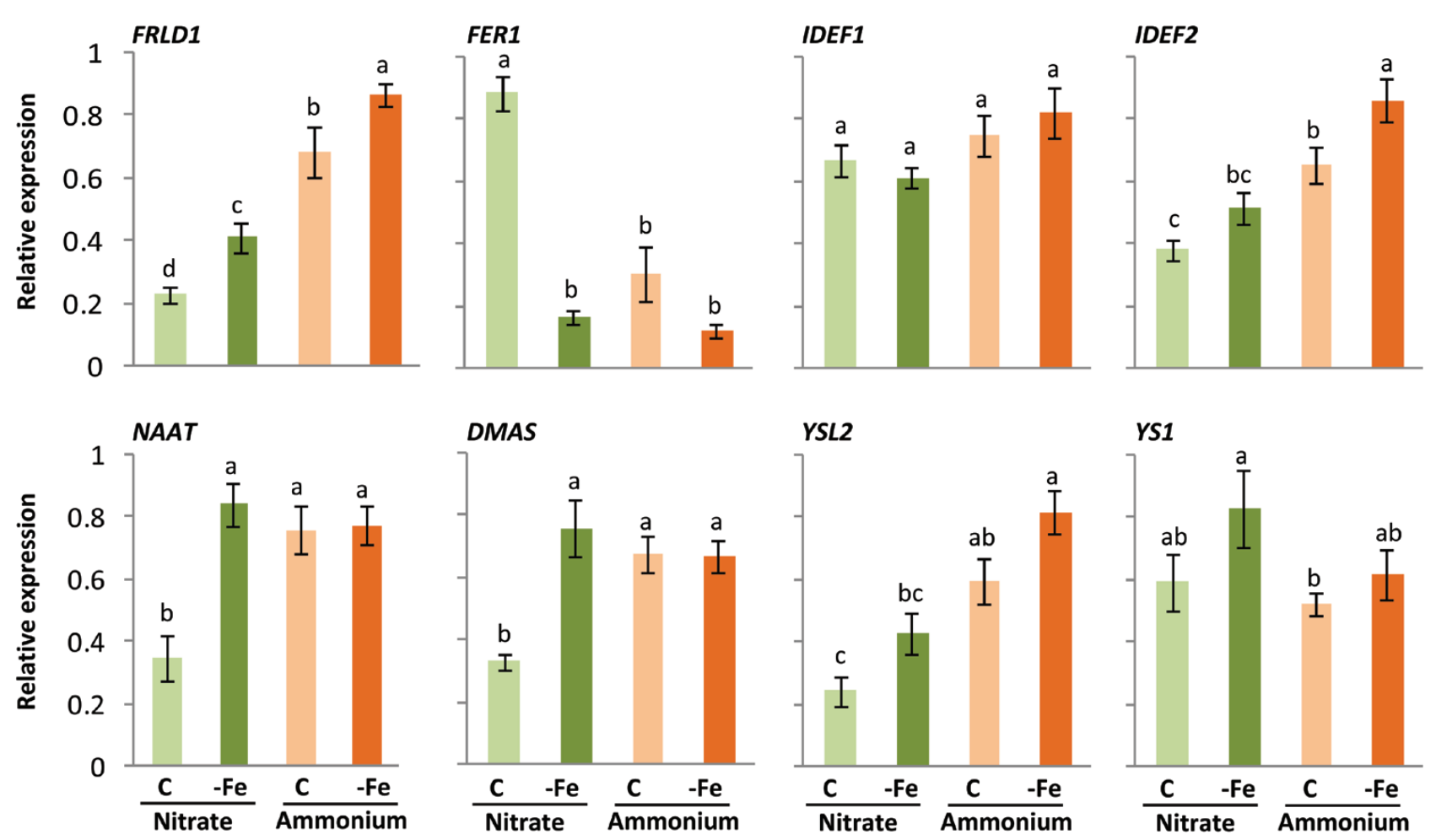

Fig. 6. Expression of Fe-related genes in roots of $B$. distachyon grown under ammonium or nitrate nutrition under control (C) or Fe deficiency (-Fe) conditions. Columns represent the mean values $\pm S E(n=6)$. Different letters indicate significant differences according to one-way ANOVA followed by Duncan's test $(P<0.05)$.

sometimes been associated with an increase of $\mathrm{Fe}^{3+}$ solubility because of ammonium-induced apoplast/rhizosphere acidification (Mengel and Geurtzen, 1988;Alloush et al., 1990; Kosegarten and Englisch, 1994; Kosegarten et al., 1998). In our work, the nutrient solution was buffered and renewed every $3-4 \mathrm{~d}$, the medium $\mathrm{pH}$ remaining quite stable (6.9-7.4) during the whole experiment. Similarly, other authors also indicate that $\mathrm{pH}$ acidification of the rhizosphere is unlikely to be the sole reason for the Fe uptake stimulation observed under ammonium nutrition (Zhu et al., 2018, 2019). Therefore, it appears clear that the higher Fe levels found in B. distachyon are associated with enhanced PS synthesis rather than with a $\mathrm{pH}$-related increase of Fe solubility.

Despite higher root Fe content, ammonium-fed B. distachyon plants displayed increased root sensitivity to Fe deficiency (Fig. 4). Thus, it appears that the accumulated $\mathrm{Fe}$ in B. distachyon roots would not be available for use by the cell or that the plant's capacity to use the absorbed $\mathrm{Fe}$ is compromised. In consequence, $\mathrm{Fe}$ deficiency responses including the Fe uptake machinery would be induced. Among others causes, reduced $\mathrm{Fe}$ availability could be due to an incorrect loading of the $\mathrm{Fe}$ from the xylem/apoplast into the cells or to perturbations in subcellular partitioning of $\mathrm{Fe}$ (Haydon et al., 2012). In this same line of evidence, lower ferritin content was also found in a proteome analysis performed in ammonium-fed Medicago truncatula plants (Royo et al., 2019). In addition, ammonium nutrition has also been observed to stimulate Fe deficiency responses in Arabidopsis (Zhu et al., 2019; Coleto et al., 2021). Indeed, recently we reported that altered Fe homeostasis could be associated with the Arabidopsis response to ammonium nutrition through a signalling pathway involving MYB28 and MYB29 transcription factors (Bejarano et al., 2021; Coleto et al., 2021). However, in contrast to the observed B. distachyon root growth decrease in ammonium-fed plants under Fe deficiency, several works reported a beneficial effect of $\mathrm{NH}_{4}{ }^{+}$ supply in response to $\mathrm{Fe}$ deprivation (Alloush et al., 1990; Kosegarten and Englisch, 1994; Kosegarten et al., 1998; Zou et al., 2001; Zhu et al., 2018, 2019). In these studies, ammonium plants were not grown under ammonium stress conditions, and thus we can hypothesize that the differences found may be associated with the degree of ammonium stress. Alternatively, a species-dependent response cannot be ruled ou.

Fe deficiency also provoked a striking increase of root $\mathrm{NH}_{4}{ }^{+}$ content (Fig. 7). Similarly, in Arabidopsis, Fe deficiency also induced $\mathrm{NH}_{4}^{+}$uptake, which was correlated with the induction of the expression of $A M T 1 ; 1$ and $A M T 1 ; 3 \mathrm{NH}_{4}^{+}$transporter genes (Zhu et al., 2019). Since excessive $\mathrm{NH}_{4}^{+}$accumulation in tissues is generally known to be detrimental for plant performance (Britto and Kronzucker, 2002; González-Moro et al., 2021), the negative effect of $\mathrm{NH}_{4}{ }^{+}$accumulation on root growth under Fe deficiency cannot be ignored. In addition, the high levels of $\mathrm{Zn}$ observed in ammonium-fed plants under Fe deficiency, associated with the stimulation of PSs combined 

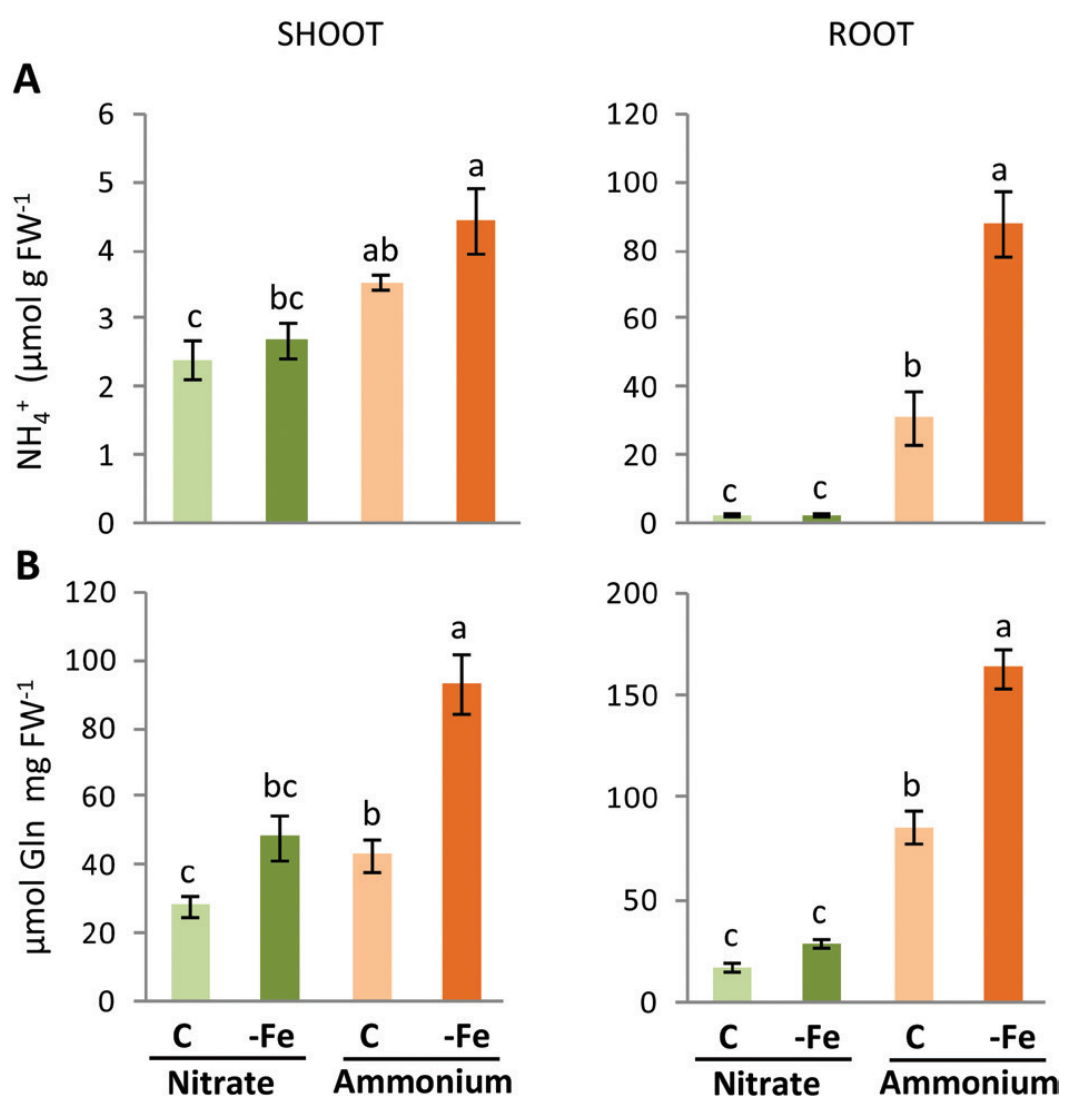

Fig. 7. Ammonium (A) and total free amino acid (B) content in B. distachyon grown under ammonium or nitrate nutrition under control (C) or Fe deficiency $(-\mathrm{Fe})$ conditions. Columns represent the mean values $\pm \mathrm{SE}(n=6)$. Different letters indicate significant differences according to one-way ANOVA followed by Duncan's test $(P<0.05)$.

with the absence of Fe to compete for these PSs, could be also detrimental for plant growth. Indeed, Zn phytotoxicity symptoms typically appear when $\mathrm{Zn}$ accumulates in the shoot in the 300-1000 ppm range (Chaney, 1993).

Altogether, in this work, we show that the adaptation of $B$. distachyon roots to ammonium nutrition involves changes in $\mathrm{C}$ and $\mathrm{N}$ metabolism, cell wall metabolism, redox homeostasis and interaction with other ions. In particular, PS synthesis was enhanced under ammonium nutrition, leading to increased $\mathrm{Fe}$ uptake. In addition, the interaction between ammonium nutrition and $\mathrm{Fe}$ metabolism was evidenced by the increased sensitivity of ammonium-fed plants to Fe deficiency. Overall, the results suggest that ammonium nutrition triggers impaired Fe utilization and transport. Future research is needed to further elucidate the mechanisms underlying the interaction between $\mathrm{Fe}$ and $\mathrm{NH}_{4}{ }^{+}$, notably regarding the mechanism leading to Fe unavailability for use by the cell, in order to better understand and improve ammonium use efficiency and tolerance in plants.

\section{Supplementary data}

The following supplementary data are available at JXB online.
Table S1. Primers used for qPCR gene expression analysis. Table S2. Biomass and chlorophyll content of Brachypodium distachyon plants grown under ammonium or nitrate nutrition.

Table S3. List of proteins identified, quantified, and differentially expressed in roots of $B$. distachyon grown under nitrate or ammonium nutrition.

Table S4. Full list of enriched GO functional classes.

Fig. S1.Volcano plot of the quantified proteins.

Fig. S2. Expression of selected genes encoding proteins related to iron homeostasis displaying differential abundance (see Fig. 1C) in the roots of B. distachyon grown under ammonium or nitrate nutrition.

Fig. S3. Met/SAM derivatives in shoots of $B$. distachyon grown under ammonium or nitrate nutrition.

Fig. S4. Expression of Fe-related genes in the shoot of $B$. distachyon grown under ammonium or nitrate nutrition under control $(\mathrm{C})$ or Fe deficiency $(-\mathrm{Fe})$ conditions

\section{Acknowledgements}

We thank Diana Cabrera from C.I.C. bioGUNE for technical assistance in Met cycle analysis, and we are grateful for the technical and human support provided by SGIker (UPV/EHU). 


\section{Author contributions}

MBGM and DM: conceptualization and supervision; MP, AJMP, LU, IC, and DM: performing the experiments and data analysis; SML and JMFP: quantifying Met derivatives; JCG and AAF: quantifying PSs; MP and DM: writing. All authors edited and approved the final manuscript.

\section{Funding}

This research was funded/supported by the Basque Government (IT932-16) and the Spanish Ministry of Economy and Competitiveness (BIO2017-84035-R and PID2020-113385RB-I00 co-funded by FEDER). MP held a doctoral scholarship (Conv. 672) associated with COLCIENCIAS (Department of Science, Technology and Innovation of Colombia) and the Department of Magdalena. LU holds a PhD grant from the Basque Government and AJMP from the Spanish Ministry of Economy and Competitiveness.

\section{Data availability}

All data supporting the findings of this study are available within the paper and within its supplementary data published online.

\section{References}

Alloush GA, Bot JL, Sanders FE, Kirkby EA. 1990. Mineral nutrition of chickpea plants supplied with $\mathrm{NO}_{3}{ }^{-}$or $\mathrm{NH}_{4}{ }^{+} \mathrm{N}$. I. Ionic balance in relation to iron stress. Journal of Plant Nutrition 13, 1575-1590.

Balkos KD, Britto DT, Kronzucker HJ. 2010. Optimization of ammonium acquisition and metabolism by potassium in rice (Oryza sativa L. CV. IR-72). Plant, Cell \& Environment 33, 23-34.

Beeckman F, Motte H, Beeckman T. 2018. Nitrification in agricultural soils: impact, actors and mitigation. Current Opinion in Biotechnology 50, 166-173.

Bejarano I, Marino D, Coleto I. 2021. Arabidopsis MYB28 and MYB29 transcription factors are involved in ammonium-mediated alterations of rootsystem architecture. Plant Signaling \& Behavior 16, 1879532.

Bouain N, Krouk G, Lacombe B, Rouached H. 2019. Getting to the root of plant mineral nutrition: combinatorial nutrient stresses reveal emergent properties. Trends in Plant Science 24, 542-552.

Briat JF, Dubos C, Gaymard F. 2015. Iron nutrition, biomass production, and plant product quality. Trends in Plant Science 20, 33-40.

Britto DT, Kronzucker HJ. 2002. $\mathrm{NH}_{4}{ }^{+}$toxicity in higher plants: a critical review. Journal of Plant Physiology 584, 567-584.

Chaney RL. 1993. Zinc phytotoxicity. In: Robson AD, ed. Zinc in soils and plants. Dordrecht: Springer Science+Business Media, 135-144.

Coleto I, Bejarano I, Marín-Peña AJ, Medina J, Rioja C, Burow M, Marino D. 2021. Arabidopsis thaliana transcription factors MYB28 and MYB29 shape ammonium stress responses by regulating Fe homeostasis. New Phytologist 229, 1021-1035.

Coleto I, de la Peña M, Rodríguez-Escalante J, Bejarano I, Glauser G, Aparicio-Tejo PM, González-Moro MB, Marino D. 2017. Leaves play a central role in the adaptation of nitrogen and sulfur metabolism to ammonium nutrition in oilseed rape (Brassica napus). BMC Plant Biology 17, 1-13.

Coskun D, Britto DT, Kronzucker HJ. 2014. The physiology of channelmediated $\mathrm{K}^{+}$acquisition in roots of higher plants. Physiologia Plantarum 151, 305-312.

Cox J, Mann M. 2008. MaxQuant enables high peptide identification rates, individualized p.p.b.-range mass accuracies and proteome-wide protein quantification. Nature Biotechnology 26, 1367-1372.
Cox J, Neuhauser N, Michalski A, Scheltema RA, Olsen JV, Mann M. 2011. Andromeda: a peptide search engine integrated into the MaxQuant environment. Journal of Proteome Research 10, 1794-1805.

Cui YN, Li XT, Yuan JZ, Wang FZ, Wang SM, Ma Q. 2019. Nitrate transporter NPF7.3/NRT1.5 plays an essential role in regulating phosphate deficiency responses in Arabidopsis. Biochemical and Biophysical Research Communications 508, 314-319.

De la Peña M, González-Moro MB, Marino D. 2019. Providing carbon skeletons to sustain amide synthesis in roots underlines the suitability of Brachypodium distachyon for the study of ammonium stress in cereals. AoB Plants 11, plzO29.

Díaz-Benito $P$, Banakar $R$, Rodríguez-Menéndez $S$, Capell $T$, Pereiro R, Christou P, Abadía J, Fernández B, Álvarez-Fernández A. 2018. Iron and zinc in the embryo and endosperm of rice (Oryza sativa L.) seeds in contrasting 2'-deoxymugineic acid/nicotianamine scenarios. Frontiers in Plant Science 9, 1190.

Gerendás J, Zhu Z, Bendixen R, Ratcliffe RG, Sattelmacher B. 1997. Physiological and biochemical processes related to ammonium toxicity in higher plants. Zeitschrift für Pflanzenernährung und Bodenkunde 160, 239-251.

Glazowska S, Baldwin L, Mravec J, Bukh C, Fangel JU, Willats WG, Schjoerring JK. 2019. The source of inorganic nitrogen has distinct effects on cell wall composition in Brachypodium distachyon. Journal of Experimental Botany 70, 6461-6473.

González-Moro MB, González-Moro I, de la Peña M, Estavillo JM, Aparicio-Tejo PM, Marino D, González-Murua C, Vega-Mas I. 2021. A multi-species analysis defines anaplerotic enzymes and amides as metabolic markers for ammonium nutrition. Frontiers in Plant Science 11, 632285.

Haydon MJ, Kawachi M, Wirtz M, Hillmer S, Hell R, Krämer U. 2012. Vacuolar nicotianamine has critical and distinct roles under iron deficiency and for zinc sequestration in Arabidopsis. The Plant Cell 24, 724-737.

Hindt MN, Guerinot ML. 2012. Getting a sense for signals: regulation of the plant iron deficiency response. Biochimica et Biophysica Acta 1823, 1521-1530.

Huérfano X, Estavillo JM, Fuertes-Mendizábal T, Torralbo F, González-Murua C, Menéndez S. 2018. DMPSA and DMPP equally reduce $\mathrm{N}_{2} \mathrm{O}$ emissions from a maize-ryegrass forage rotation under Atlantic climate conditions. Atmospheric Environment 187, 255-265.

Kellogg EA. 2015. Brachypodium distachyon as a genetic model system. Annual Review of Genetics 49, 1-20.

Kobayashi T, Nozoye T, Nishizawa NK. 2019. Iron transport and its regulation in plants. Free Radical Biology \& Medicine 133, 11-20.

Kobayashi T, Suzuki M, Inoue H, Itai RN, Takahashi M, Nakanishi H, Mori S, Nishizawa NK. 2005. Expression of iron-acquisition-related genes in iron-deficient rice is co-ordinately induced by partially conserved iron-deficiency-responsive elements. Journal of Experimental Botany 56, 1305-1316.

Kosegarten H, Englisch G. 1994. Effect of various nitrogen forms on the $\mathrm{pH}$ in leaf apoplast and on iron chlorosis of Glycine max L. Zeitschrift für Pflanzenernährung und Bodenkunde 157, 401-405.

Kosegarten H, Schwed U, Wilson G, Mengel K. 1998. Comparative investigation on the susceptibility of faba bean (Vicia faba L.) and sunflower (Helianthus annuus L.) to iron chlorosis. Journal of Plant Nutrition 21, 1511-1528.

Loulakakis KA, Roubelakis-Angelakis KA. 1991. Plant NAD(H)glutamate dehydrogenase consists of two subunit polypeptides and their participation in the seven isoenzymes occurs in an ordered ratio. Plant Physiology 97, 104-111.

Ma JF, Shinada T, Matsuda C, Nomoto K. 1995. Biosynthesis of phytosiderophores, mugineic acids, associated with methionine cycling. Journal of Biological Chemistry 270, 16549-16554.

Marschner H. 2012. Marschner's mineral nutrition of higher plants. New York: Academic Press.

Medici A, Marshall-Colon A, Ronzier E, Szponarski W, Wang R, Gojon A, Crawford NM, Ruffel S, Coruzzi GM, Krouk G. 2015. AtNIGT1/ 
HRS1 integrates nitrate and phosphate signals at the Arabidopsis root tip. Nature Communications 6, 6274.

Mengel K, Geurtzen G. 1988. Relationship between iron chlorosis and alkalinity in Zea mays. Physiologia Plantarum 72, 460-465.

Ogawa S, Mitsuya S. 2012. S-methylmethionine is involved in the salinity tolerance of Arabidopsis thaliana plants at germination and early growth stages. Physiologia Plantarum 144, 13-19.

Podgórska A, Burian M, Gieczewska K, Ostaszewska-Bugajska M, Zebrowski J, Solecka D, Szal B. 2017. Altered cell wall plasticity can restrict plant growth under ammonium nutrition. Frontiers in Plant Science 8, 1344.

Ricachenevsky FK, Sperotto RA. 2014. There and back again, or always there? The evolution of rice combined strategy for Fe uptake. Frontiers in Plant Science 5, 189.

Roosta HR, Schjoerring JK. 2007. Effects of ammonium toxicity on nitrogen metabolism and elemental profile of cucumber plants. Journal of Plant Nutrition 30, 1933-1951.

Royo B, Esteban R, Buezo J, Santamaría E, Fernández-Irigoyen J, Becker D, Moran JF. 2019. The proteome of Medicago truncatula in response to ammonium and urea nutrition reveals the role of membrane proteins and enzymes of root lignification. Environmental and Experimental Botany 162, 168-180.

Sarasketa A, González-Moro MB, González-Murua C, Marino D. 2016. Nitrogen source and external medium pH interaction differentially affects root and shoot metabolism in Arabidopsis. Frontiers in Plant Science 7, 29
Sauter M, Moffatt B, Saechao MC, Hell R, Wirtz M. 2013. Methionine salvage and S-adenosylmethionine: essential links between sulfur, ethylene and polyamine biosynthesis. The Biochemical Journal 451, 145-154.

Thomson CJ, Marschner H, Römheld V. 1993. Effect of nitrogen fertilizer form on $\mathrm{pH}$ of the bulk soil and rhizosphere, and on the growth, phosphorus, and micronutrient uptake of bean. Journal of Plant Nutrition 16 493-506.

Tyanova S, Temu T, Sinitcyn P, Carlson A, Hein MY, Geiger T, Mann M, Cox J. 2016. The Perseus computational platform for comprehensive analysis of (prote)omics data. Nature Methods 13, 731-740.

Van Beusichem ML, Kirkby EA, Baas R. 1988. Influence of nitrate and ammonium nutrition on the uptake, assimilation, and distribution of nutrients in Ricinus communis. Plant Physiology 86, 914-921.

Zhu CQ, Zhang JH, Zhu LF, et al. 2018. $\mathrm{NH}_{4}{ }^{+}$facilitates iron reutilization in the cell walls of rice (Oryza sativa) roots under iron-deficiency conditions. Environmental and Experimental Botany 151, 21-31.

Zhu CQ, Zhu XF, Hu AY, Wang C, Wang B, Dong XY, Shen RF. 2016. Differential effects of nitrogen forms on cell wall phosphorus remobilization are mediated by nitric oxide, pectin content, and phosphate transporter expression. Plant Physiology 171, 1407-1417.

Zhu XF, Dong XY, Wu Q, Shen RF. 2019. Ammonium regulates Fe deficiency responses by enhancing nitric oxide signaling in Arabidopsis thaliana. Planta 250, 1089-1102.

Zou C, Shen J, Zhang F, Guo S, Rengel Z, Tang C. 2001. Impact of nitrogen form on iron uptake and distribution in maize seedlings in solution culture. Plant and Soil 235, 143-149. 